\title{
Preparation Optimization and Performance Evaluation of Waterborne Epoxy Resin for Roads
}

\author{
Fei Wang, ${ }^{1}$ Hao Fu $\mathbb{D}^{2},{ }^{2}$ Guixiang Liu, ${ }^{3}$ Chaohui Wang $\mathbb{D}^{2},{ }^{2}$ and Sixin $\mathbf{Y u}^{3}$ \\ ${ }^{1}$ Shandong Hi-Speed Group Co., Ltd., Jinan 250101, China \\ ${ }^{2}$ School of Highway, Chang'an University, Xi'an 710064, China \\ ${ }^{3}$ Shandong Hi-Speed Transportation Construction Group Co., Ltd., Jinan 250101, China \\ Correspondence should be addressed to Hao Fu; 2019021038@chd.edu.cn and Chaohui Wang; wchh0205@chd.edu.cn
}

Received 21 July 2021; Revised 3 September 2021; Accepted 6 September 2021; Published 17 September 2021

Academic Editor: Marco Corradi

Copyright (C) 2021 Fei Wang et al. This is an open access article distributed under the Creative Commons Attribution License, which permits unrestricted use, distribution, and reproduction in any medium, provided the original work is properly cited.

To further improve the road performance of waterborne epoxy resin, it was prepared by using the phase inversion method. The tensile properties, bending properties, impact resistance, and storage stability of waterborne epoxy resin were determined. The bonding properties of waterborne epoxy resin were analyzed. At the same time, their properties were compared with those of waterborne epoxy resin prepared by using the curing agent emulsification method. The performance of waterborne epoxy resin was comprehensively evaluated based on multi-index grey target decision model. The results show that the optimum preparation parameters for the preparation of waterborne epoxy resin by phase inversion method are shear time $1.5 \mathrm{~h}$, shear temperature $60^{\circ} \mathrm{C}$, and shear rate 1300-1500 r/min. The suitable contents of emulsifier A and B are $18 \%$ and $16 \%$, respectively. The tensile strength, elongation at break, bending strength, bending deformation, and impact strength of waterborne epoxy resin prepared by emulsifier A can reach $34.46 \mathrm{MPa}, 12.96 \%, 85.37 \mathrm{MPa}, 19.42 \mathrm{~mm}$, and $15.66 \mathrm{~kJ} / \mathrm{m}^{2}$, respectively. It shows improved mechanical strength, deformation ability, impact resistance, and bonding performance. The comprehensive properties of waterborne epoxy resin prepared by emulsifier A are the best. It is suggested to use phase inversion method to prepare waterborne epoxy resin for roads.

\section{Introduction}

Epoxy resin has been widely used in chemical coatings, civil construction, and other fields for a long time due to its excellent mechanical properties, thermal stability, and adhesion [1-4]. However, the traditional solvent-based epoxy resin contains a lot of organic solvents, which can cause serious environmental pollution and harm human health. It is becoming increasingly difficult to meet the higher requirements of the society for green environmental protection. Waterborne epoxy resin means that the epoxy resin can be dispersed evenly in water in the form of small droplets in a proper way, thus forming a stable and uniform emulsion system. It not only has many excellent properties of traditional solvent-based epoxy resin but also has remarkable characteristics of low volatile organic compounds (VOC), convenient construction, and safety.
In recent years, some researches and applications of waterborne epoxy resin have been carried out in the field of road engineering [5]. Chen et al. [6-13] used the curing agent emulsification method to prepare the waterborne epoxy resin. The tensile, bending, and bonding properties of waterborne epoxy resin were explored, and the waterborne epoxy resin modified emulsified asphalt was further prepared. Ji et al. [14-16] used waterborne epoxy resin modified emulsified asphalt as binder for micro surfacing and coldmixed repair materials, and the mixture shows improved high temperature stability and water stability. Li et al. [17] prepared waterborne epoxy resin modified foamed asphalt cold recycled mixture, and compared with the ordinary foamed asphalt cold recycled mixture, its water resistance performance increased by $10 \%$. Liu et al. $[18,19]$ studied the waterproof performance, high temperature, low temperature, and water immersion interlayer shear strength of 
waterborne epoxy resin modified emulsified asphalt bridge deck pavement waterproof bonding layer. The results showed that the waterborne epoxy resin improves the cohesive force and viscoelastic properties of emulsified asphalt, and its properties are obviously better than those of SBR modified emulsified asphalt. Li et al. [20, 21] characterized the curing behavior of waterborne epoxy resin in emulsified asphalt by Fourier transform infrared spectroscopy (FT-IR) and evaluated the rheological properties and anti-fatigue properties of evaporated residue of modified emulsified asphalt by dynamic shear rheometer (DSR). It shows that the bonding performance, mechanical strength, and fatigue life of emulsified asphalt can be significantly improved by adding waterborne epoxy resin. The above research shows that waterborne epoxy resin is an excellent emulsified asphalt modifier, which can effectively improve the application effect of emulsified asphalt in the field of road engineering. But at present, in the field of road engineering, most of the researchers directly study the application performance of the commercially available waterborne epoxy resin, or directly study the road performance of waterborne epoxy resinmodified emulsified asphalt. There is a lack of systematic understanding and research on the tensile, bending, and bonding properties of waterborne epoxy resin.

The current preparation methods of waterborne epoxy resin include mechanical method, phase inversion method, chemical modification method, and curing agent emulsification method [22]. The size of dispersed phase particles of waterborne epoxy resin prepared by using the mechanical method is large and unevenly distributed, which leads to precipitation and poor stability. Phase inversion method [23] refers to the modification of epoxy resin from water in oil state to oil in water state by adding emulsifier through physical action. Chen et al. [24] used epoxy resin, trimellitic anhydride, and polyethylene glycol to prepare reactive epoxy resin emulsifier containing carboxyl and hydroxyl groups, and the waterborne epoxy resin was prepared by using the phase inversion method. The average particle size of emulsion was about $312 \mathrm{~nm}$. The waterborne epoxy resin prepared by using the phase inversion method has uniform particle size, narrow particle size distribution, and better stability. Chemical modification method [22] is through esterification reaction, etherification reaction, or graft reaction; the hydrophilic groups such as carboxyl group, hydroxyl group, and amine group are incorporated into the molecular structure of epoxy resin, making the modified epoxy resin hydrophilic. However, the preparation process is complex, the reaction is not controllable, and the production cost is high. Curing agent emulsification method $[7,8]$ refers to the waterborne epoxy resin curing agent, which has the properties of both curing agent and emulsifier. However, at present, the research on the preparation of waterborne epoxy resin is mainly based on the particle size, stability, and film-forming properties of the emulsion. There are few studies on the optimization of waterborne epoxy resin preparation from the perspective of the tensile, bending, and bonding properties of waterborne epoxy resin. It is necessary to further develop the preparation optimization and performance evaluation of waterborne epoxy resin based on its mechanical strength, flexibility, and bonding properties.
Based on this, to further improve the road performance of waterborne epoxy resin, it was prepared by using the phase inversion method. The effects of preparation parameters on the properties of waterborne epoxy resin were explored. The tensile properties, bending properties, impact resistance, and storage stability of waterborne epoxy resin were determined. The bonding properties of waterborne epoxy resin were analyzed. The performance of waterborne epoxy resin was comprehensively evaluated based on multiindex grey target decision model. It provides a reference for the further application of waterborne epoxy resin in road engineering.

\section{Test Materials and Methods}

2.1. Raw Materials. The bisphenol A epoxy resin E-51 supported by Nan Ya Plastics Corp (NPC) was used. It is liquid at room temperature. Waterborne epoxy resin was prepared by using the phase inversion method. Two kinds of nonionic active epoxy resin emulsifiers A and B supported by Shenzhen Kaist New Material Co., Ltd. were selected. According to previous research [8], modified alicyclic amine waterborne epoxy resin curing agent supported by Nan Ya Plastics Corp (NPC) was used. The content of curing agent for waterborne epoxy resin is considered according to the interaction between active hydrogen on the amine group of curing agent and an epoxy group phase of epoxy resin [11]. The main technical indexes of each material are shown in Table 1.

2.2. Preparation of Waterborne Epoxy Resin. Phase inversion method [23] refers to the modification of epoxy resin from water in oil state to oil in water state by adding emulsifier through physical action. The waterborne epoxy resin was prepared by using the phase inversion method, and the performance test specimens of waterborne epoxy resin were further prepared. The specific preparation process is as follows:

(1) The epoxy resin, emulsifier, water, etc., were heated to the specified temperature, and a certain weight of epoxy resin and emulsifier were weighed. The emulsifier and epoxy resin were evenly mixed by using a shear apparatus at the rate of $700-800 \mathrm{r} / \mathrm{min}$ for $15 \mathrm{~min}$.

(2) The shear apparatus was adjusted to the specified rate. Water was added through a separating funnel. After water equivalent to the specified weight was added, the shear apparatus continued to shear and disperse for a certain period of time. During the emulsification process, the temperature and shear time of the emulsion were strictly controlled.

To optimize the preparation process parameters of waterborne epoxy resin, the effects of shear time, shear temperature, shear rate, and emulsifier content on the tensile properties, bending properties, impact resistance, and storage stability of waterborne epoxy resin were investigated. According to the existing research results [22-24], three 
TABLE 1: The main technical indexes of each material.

\begin{tabular}{|c|c|c|}
\hline No. & Materials & Basic performance indices \\
\hline 1 & Epoxy resin E-51 & $\begin{array}{l}\text { Transparent viscous liquid; molecular weight, } 350-400 \text {; epoxy value, } 0.48-0.54 \text { (mol/100 g); organic } \\
\text { chlorine, } \leq 0.02 \text { (mol/100 g); inorganic chlorine, } \leq 0.001 \text { (mol } / 100 \mathrm{~g}) ; \text { volatile, } \leq 2 \%\end{array}$ \\
\hline 2 & Emulsifier A & $\begin{array}{l}\text { Colorless transparent liquid; solid content, } 50 \pm 2 \% \text {; viscosity }\left(25^{\circ} \mathrm{C}\right), 320-430 \mathrm{MPa} \cdot \mathrm{s} ; \mathrm{PH} \text { value, 6-7; } \\
\text { specific gravity, } 1.03-1.05 \mathrm{~g} / \mathrm{cm}^{3}\end{array}$ \\
\hline 3 & Emulsifier B & $\begin{array}{c}\text { Yellowish transparent liquid; solid content, } 50 \pm 2 \% \text {; viscosity }\left(25^{\circ} \mathrm{C}\right), 250-380 \mathrm{MPa} \cdot \mathrm{s} ; \mathrm{PH} \text { value, 6-8; } \\
\text { specific gravity, } 1.02-1.04 \mathrm{~g} / \mathrm{cm}^{3}\end{array}$ \\
\hline 4 & $\begin{array}{l}\text { Waterborne epoxy resin } \\
\text { curing agent }\end{array}$ & $\begin{array}{l}\text { Nonionic yellowish transparent liquid; solid content, } 50 \pm 2 \% \text {; active hydrogen equivalent (solids), } \\
291 \text {; viscosity }\left(25^{\circ} \mathrm{C}\right), 10 \mathrm{~Pa} \cdot \mathrm{s} \text {; } \mathrm{PH} \text { value, } 11-13 \text {; specific gravity, } 1.05-1.10 \mathrm{~g} / \mathrm{cm}^{3}\end{array}$ \\
\hline
\end{tabular}

shear times of $1.0 \mathrm{~h}, 1.5 \mathrm{~h}$, and $2.0 \mathrm{~h}$; three shear temperatures of $55^{\circ} \mathrm{C}, 60^{\circ} \mathrm{C}$, and $65^{\circ} \mathrm{C}$; three shear rates of 900-1100 r/ $\mathrm{min}, 1100-1300 \mathrm{r} / \mathrm{min}$, and $1300-1500 \mathrm{r} / \mathrm{min}$; and four emulsifier contents of $14 \%, 16 \%, 18 \%$, and $20 \%$ were set to comprehensively study the effects of preparation process parameters and emulsifier content on the properties of waterborne epoxy resin.

2.3. Performance Test of Waterborne Epoxy Resin. Based on the tensile properties, bending properties, impact resistance, and storage stability of waterborne epoxy resin, the preparation process of waterborne epoxy resin was optimized, and the bonding properties of waterborne epoxy resin were evaluated. The properties of the waterborne epoxy resin were compared with those of waterborne epoxy resin prepared by using the curing agent emulsification method. Five samples were tested in each group, and the average value of three valid data was taken as the final test result. The performance test scheme of waterborne epoxy resin is shown in Figure 1.

2.3.1. Tensile Test. The tensile strength and elongation at break were used to evaluate the mechanical strength and deformation ability of waterborne epoxy resin. The prepared waterborne epoxy resin emulsion was uniformly poured into the tetrafluoroethylene dumbbell mold coated with demoulding agent. The specimens were placed in $40^{\circ} \mathrm{C}$ constant temperature oven for $4 \mathrm{~h}$, then demoulded and placed in $25^{\circ} \mathrm{C}$ constant temperature oven for 7 days. Then, the $25^{\circ} \mathrm{C}$ tensile properties were tested by using the universal material testing machine, and the tensile rate was $10 \mathrm{~mm} /$ min. The tensile strength and elongation at break are calculated according to Equations (1) and (2), respectively.

$$
\begin{aligned}
\sigma_{t} & =\frac{p}{b \cdot h}, \\
\varepsilon_{t} & =\frac{\Delta L_{b}}{L_{0}} \times 100,
\end{aligned}
$$

where $\sigma_{t}$ is the tensile strength, MPa; $P$ is the breaking load, $\mathrm{N} ; b$ is the specimen width, $\mathrm{mm} ; h$ is the specimen thickness, $\mathrm{mm} ; \varepsilon_{t}$ is the specimen elongation at breaking, $\% ; L_{0}$ is the measured standard length of the specimen, $\mathrm{mm} ; \Delta L_{b}$ is the elongation to the measured standard length of the specimen, $L_{0}$, when the specimen breaks, mm.
2.3.2. Bending Test. The bending strength and bending deformation of the waterborne epoxy resin were tested to evaluate its deformation resistance and toughness. The prepared waterborne epoxy resin emulsion was uniformly poured into a tetrafluoroethylene strip mold $(80 \mathrm{~mm} \times$ $15 \mathrm{~mm} \times 4 \mathrm{~mm})$. The specimens were placed in $40^{\circ} \mathrm{C}$ constant temperature oven for $4 \mathrm{~h}$, then demoulded and placed in $25^{\circ} \mathrm{C}$ constant temperature oven for 7 days. Then, the $25^{\circ} \mathrm{C}$ three-point bending test was carried out for each specimen, and the loading rate was $10 \mathrm{~mm} / \mathrm{min}$. The bending strength is calculated according to

$$
\sigma_{b}=\frac{3 p \cdot l}{2 b \cdot h^{2}}
$$

where $\sigma_{b}$ is the bending strength, $\mathrm{MPa} P$ is the failure load, $\mathrm{N} ; l$ is the span, $\mathrm{mm} ; b$ is the specimen width, $\mathrm{mm} ; h$ is the specimen thickness, $\mathrm{mm}$.

2.3.3. Impact Test. The impact strength was used to evaluate the impact resistance of waterborne epoxy resin according to the Test methods for properties of resin casting body $(\mathrm{GB} / \mathrm{T}$ 2567-2008), China. The prepared waterborne epoxy resin emulsion was uniformly poured into a tetrafluoroethylene strip mold $(80 \mathrm{~mm} \times 10 \mathrm{~mm} \times 4 \mathrm{~mm})$. The specimens were placed in $40^{\circ} \mathrm{C}$ constant temperature oven for $4 \mathrm{~h}$, then demoulded and placed in $25^{\circ} \mathrm{C}$ constant temperature oven for 7 days. Then, the $25^{\circ} \mathrm{C}$ impact test was carried out with a simple beam impact instrument immediately. The impact strength is calculated according to

$$
\sigma_{k}=\frac{1000 A}{b \times d}
$$

where $\sigma_{k}$ is the impact strength, $\mathrm{kJ} / \mathrm{m}^{2}$; A is the energy consumed by the specimen, $\mathrm{J} ; b$ is the width of the test piece, $\mathrm{mm} ; d$ is the thickness of the test piece, $\mathrm{mm}$.

2.3.4. Storage Stability Test. Insufficient storage stability of waterborne epoxy resin will cause segregation and delamination, which will further affect the mechanical properties of the cured product. The newly prepared $50 \mathrm{~mL}$ waterborne epoxy resin was added into the $50 \mathrm{~mL}$ measuring cylinder, the mouth of the measuring cylinder was sealed, and it was placed in the $25^{\circ} \mathrm{C}$ temperature constant temperature curing box. The volume of the supernatant was observed after 15 days and 30 days, and the volume of the supernatant was 


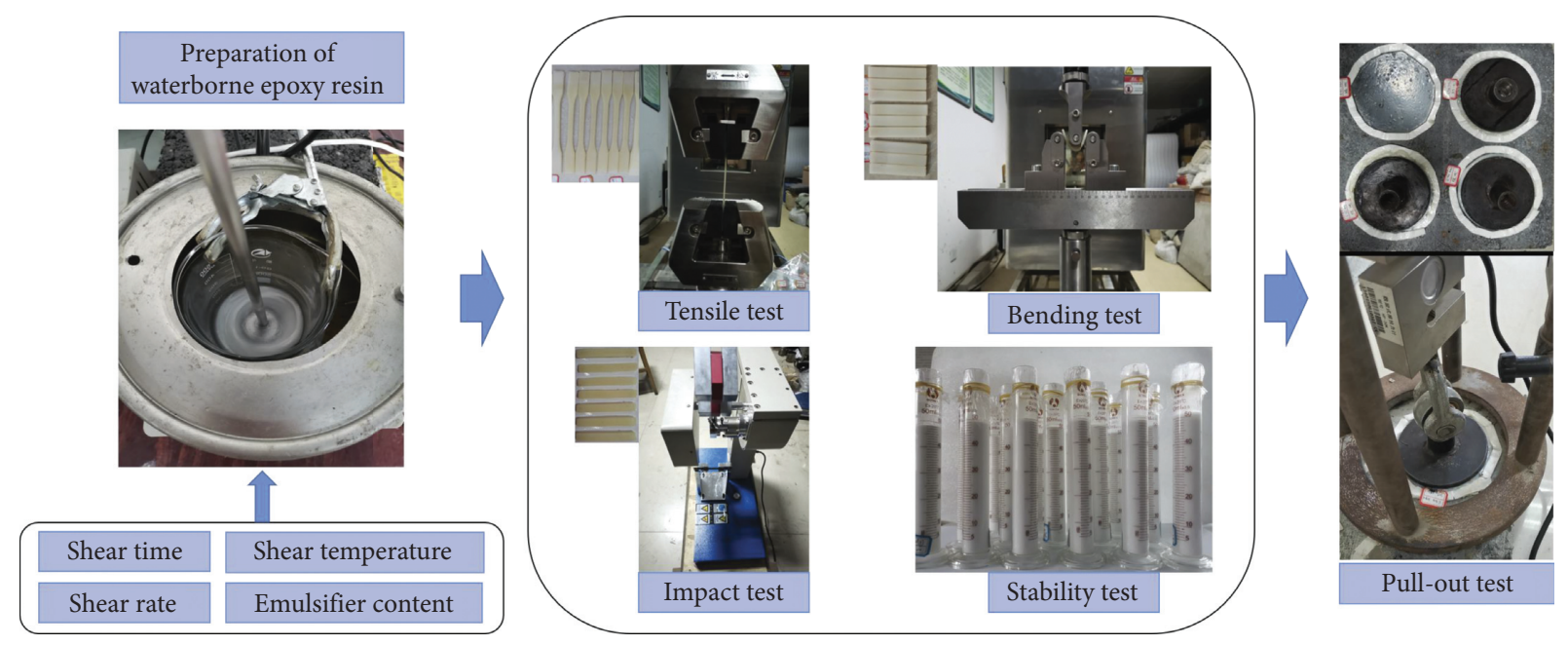

FIGURE 1: The performance test scheme of waterborne epoxy resin.

used as an evaluation index for the storage stability of the waterborne epoxy resin emulsion.

2.3.5. Bonding Performance Test. Referring to water quality asphalt waterproof coating for highway (JT/T 535-2015), the bonding performance of waterborne epoxy resin was evaluated by pull-out strength. The prepared waterborne epoxy resin was evenly distributed on the surface of cement concrete specimens with strength grade above C30 according to the amount of $1.0 \mathrm{~kg} / \mathrm{m}^{2}$, and cured for 7 days at $25^{\circ} \mathrm{C}$. Then, the quick drying $\mathrm{AB}$ adhesive was used to bond the puller to the surface of the cured specimen. Next, the specimens were kept at $-10^{\circ} \mathrm{C}, 25^{\circ} \mathrm{C}$, and $40^{\circ} \mathrm{C}$ in constant temperature ovens for $4 \mathrm{~h}$, respectively, and the pull-out strength was tested by the pull-out tester with the loading rate of $10 \mathrm{~mm} / \mathrm{min}$.

\section{Results and Discussion}

3.1. Effect of Different Process Parameters on the Performance of Waterborne Epoxy Resin. Based on the evaluation indexes of tensile strength, elongation at break, bending strength, bending deformation, impact strength, and stability, the effects of various preparation process parameters on the properties of waterborne epoxy resin were comprehensively explored. The tensile properties, bending properties, impact resistance, and storage stability of waterborne epoxy resin were clarified, so as to further optimize the preparation process of waterborne epoxy resin.

3.1.1. Shear Time. Taking the preparation of waterborne epoxy resin with emulsifier A content of $18 \%$ as an example, the shear temperature and shear rate were set at $60^{\circ} \mathrm{C}$ and $1300-1500 \mathrm{r} / \mathrm{min}$, respectively. The tensile properties, bending properties, impact resistance, and stability of the waterborne epoxy resin prepared under each shear time were tested, and the influence of shear time on the properties of waterborne epoxy resin was determined. The test results are shown in Figure 2.
It can be seen from Figure 2 that with the increase of shear time, the properties of waterborne epoxy resin prepared with emulsifier A increase first and then decrease. When the shear time is $1.5 \mathrm{~h}$, its properties reach a better level. When the shear time increased from $1.0 \mathrm{~h}$ to $1.5 \mathrm{~h}$, the tensile strength, elongation at break, bending strength, bending deformation, and impact strength of waterborne epoxy resin increased by $6.4 \%, 61.8 \%, 19.7 \%, 78.2 \%$, and $17.2 \%$, respectively. The analysis shows that with the increase of the shear time, the waterborne epoxy resin will have enough time to shear and disperse after the water in oil state is changed to the oil in water, so that the particle size and stability of the emulsion will become better. However, as the shear time continues to increase, excessive shearing leads to the mechanical demulsification of waterborne epoxy resin to a certain extent, the particle size of emulsion increases, the stability becomes worse, and the properties of cured products decrease. Therefore, it is suggested that the shear time for the preparation of waterborne epoxy resin by using the phase inversion method is $1.5 \mathrm{~h}$.

3.1.2. Shear Temperature. Taking the preparation of waterborne epoxy resin with emulsifier A content of $18 \%$ as an example, the shear time and shear rate were set at $1.5 \mathrm{~h}$ and $1300-1500 \mathrm{r} / \mathrm{min}$, respectively. The tensile properties, bending properties, impact resistance, and stability of the waterborne epoxy resin prepared under each shear temperature were tested, and the influence of shear temperature on the properties of waterborne epoxy resin was determined. The test results are shown in Figure 3.

As shown in Figure 3, with the increase of shear temperature, the properties of waterborne epoxy resin prepared by emulsifier A increase first and then decrease. When the shear temperature is $60^{\circ} \mathrm{C}$, its properties reach a better level. When the shear temperature increases from $55^{\circ} \mathrm{C}$ to $60^{\circ} \mathrm{C}$, the tensile strength, elongation at break, bending strength, bending deformation, and impact strength of waterborne epoxy resin increase by $0.2 \%$, 


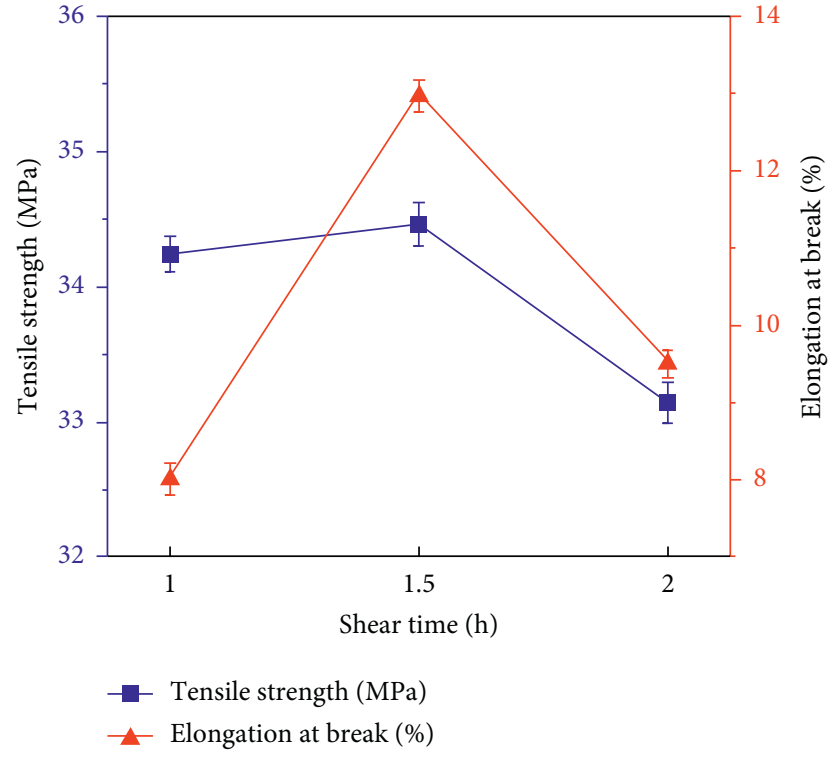

(a)

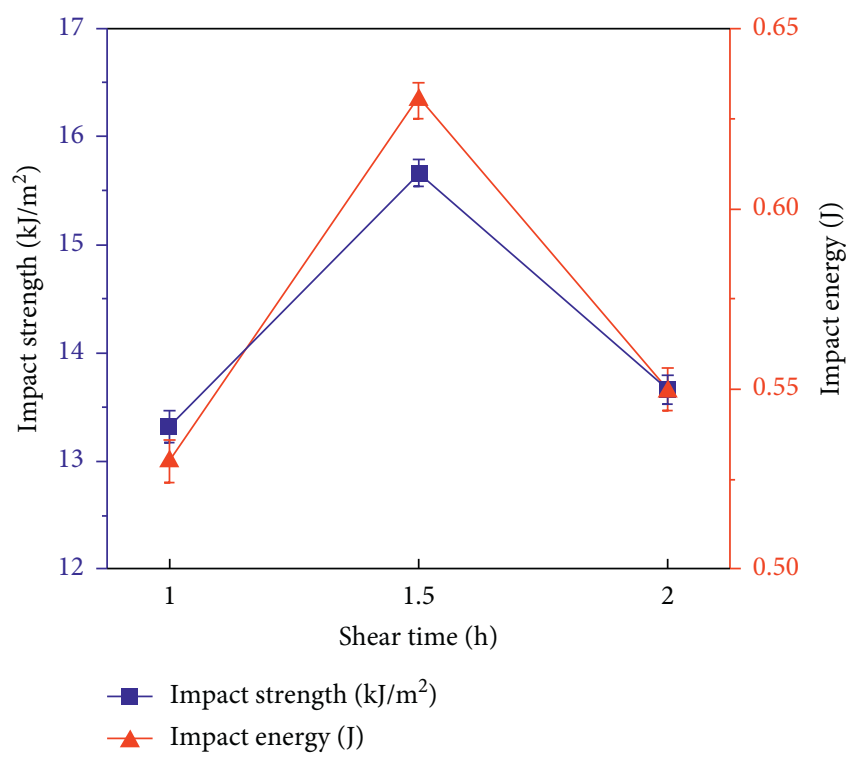

(c)

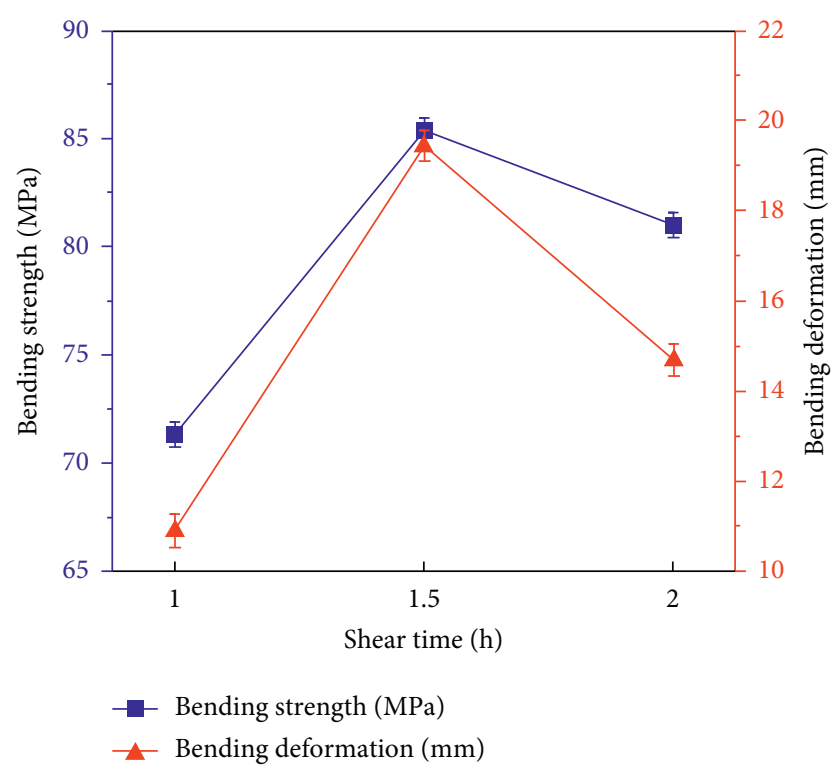

(b)

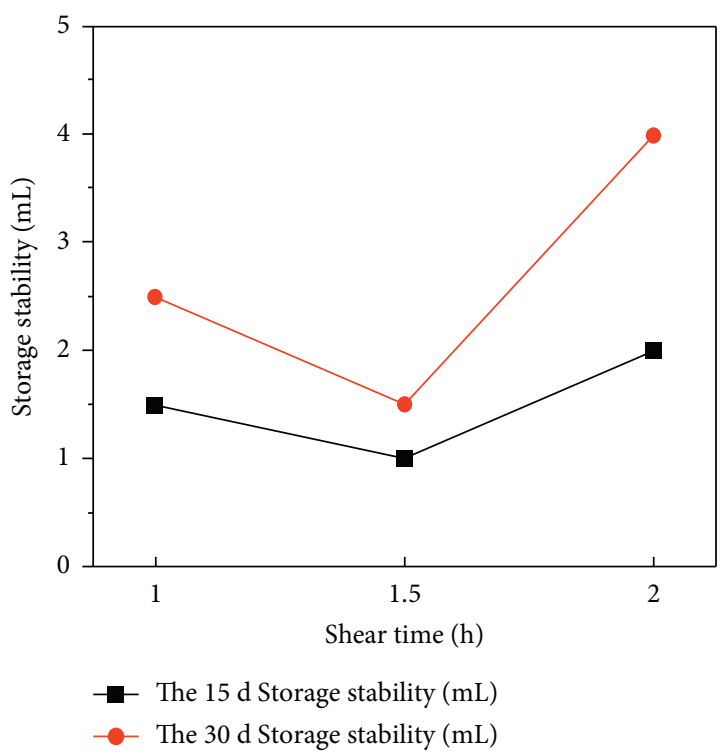

(d)

Figure 2: Effect of shear time on properties of emulsifier A emulsifying E-51 epoxy resin: (a) Tensile properties; (b) bending properties; (c) impact properties; (d) stability.

$63.8 \%, 14.3 \%, 59.4 \%$, and $41.1 \%$, respectively. In the preparation process of waterborne epoxy resin, low shear temperature is conducive to phase inversion, but the viscosity of the system is higher at low temperature, which is not conducive to uniform dispersion and poor emulsification effect. When the shear temperature is too high, the viscosity of the system decreases, which helps to emulsify and disperse evenly. However, under high temperature, the thermal movement of the emulsion particles is aggravated, and the droplets easily collide and gather. Finally, the particle size of the epoxy resin emulsion increases and the stability decreases. Therefore, it is suggested that the shear temperature of waterborne epoxy resin prepared by using the phase inversion method is $60^{\circ} \mathrm{C}$.
3.1.3. Shear Rate. Taking the preparation of waterborne epoxy resin with emulsifier A content of $18 \%$ or emulsifier B content of $16 \%$ as examples, the shear time and shear temperature were set at $1.5 \mathrm{~h}$ and $60^{\circ} \mathrm{C}$, respectively. The tensile properties, bending properties, impact resistance, and stability of the waterborne epoxy resin prepared under each shear rate were tested, and the influence of shear rate on the properties of waterborne epoxy resin was determined. The test results are shown in Figures 4 and 5.

It can be seen from Figures 4 and 5 that with the increase of shear rate, the properties of waterborne epoxy resin prepared with emulsifier A or emulsifier B increase gradually. When the shear rate is increased from 900-1100 $\mathrm{r} / \mathrm{min}$ to $1300-1500 \mathrm{r} / \mathrm{min}$, the tensile properties, bending 


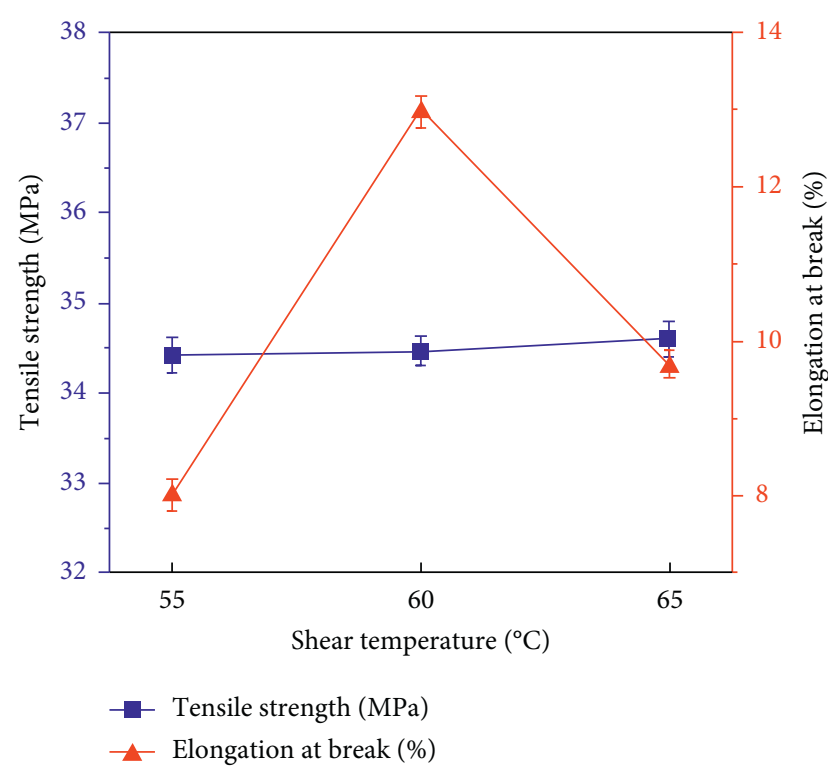

(a)

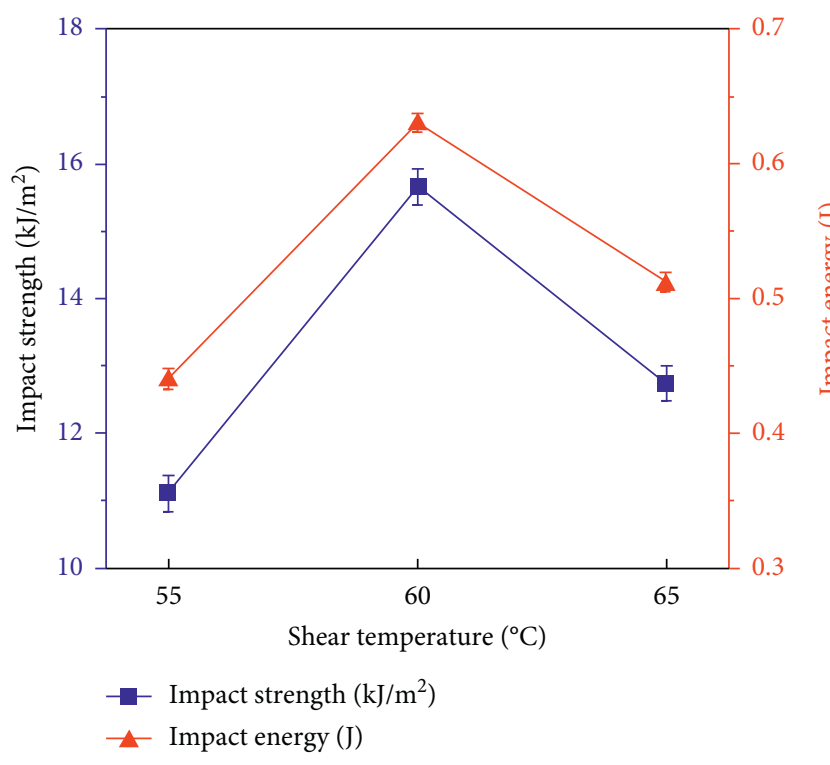

(c)

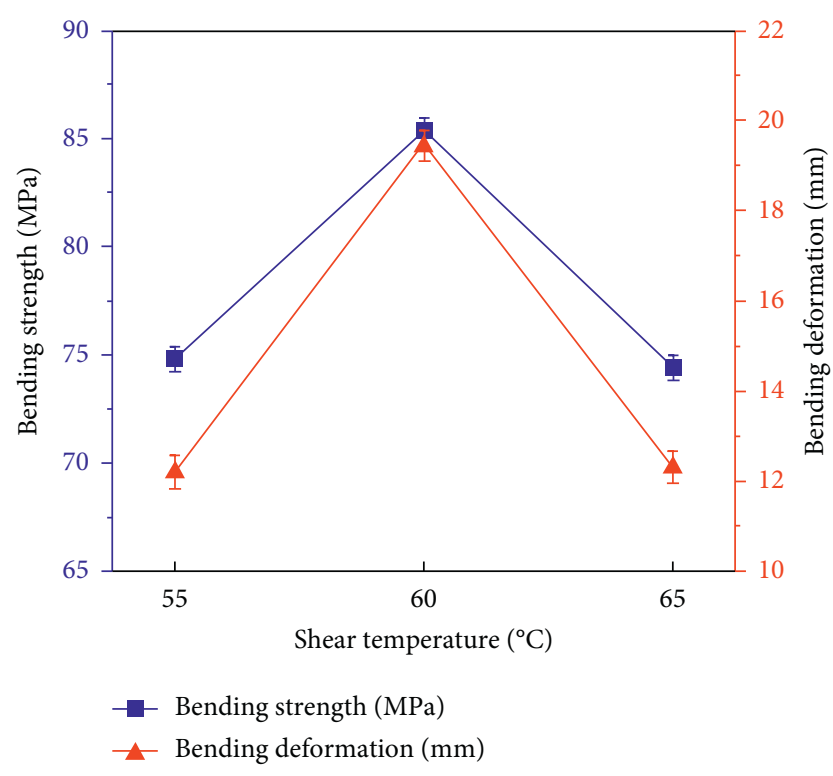

(b)

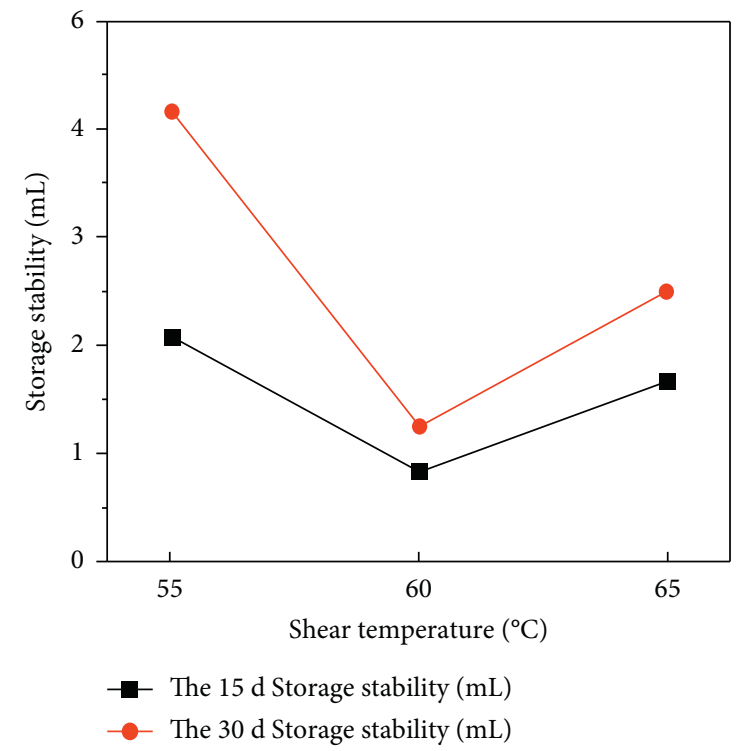

(d)

Figure 3: Effect of shear temperature on properties of emulsifier A emulsifying E-51 epoxy resin: (a) Tensile properties; (b) bending properties; (c) impact properties; (d) stability.

properties, and impact resistance of waterborne epoxy resin prepared with emulsifier A increased by 21.6-25.3\%, $13.3-33.7 \%$, and $14.7 \%$, respectively, and the tensile strength, elongation at break, bending strength, bending deformation, and impact strength were $34.46 \mathrm{MPa}, 12.96 \%$, $85.37 \mathrm{MPa}, 19.42 \mathrm{~mm}$, and $15.66 \mathrm{~kJ} / \mathrm{m}^{2}$, respectively. The storage stability is obviously improved, and the supernatant after standing for 15 days changed from $10 \mathrm{~mL}$ to $1 \mathrm{~mL}$. The results show that with the increase of shear rate, the emulsification effect of waterborne epoxy resin gradually becomes better, so as to improve its properties. However, considering that too fast shear rate will lead to mechanical demulsification and economy, it is suggested that the shear rate of waterborne epoxy resin prepared by using the phase inversion method is $1300-1500 \mathrm{r} / \mathrm{min}$.

In conclusion, the suitable process parameters for the preparation of waterborne epoxy resin by using the phase inversion method are shear time $1.5 \mathrm{~h}$, shear temperature $60^{\circ} \mathrm{C}$, and shear rate $1300-1500 \mathrm{r} / \mathrm{min}$.

3.2. Effect of Emulsifier Content on the Performance of Waterborne Epoxy Resin. The waterborne epoxy resin was prepared with the optimized process parameters. The tensile properties, bending properties, impact properties, and storage stability of waterborne epoxy resin were tested. The 


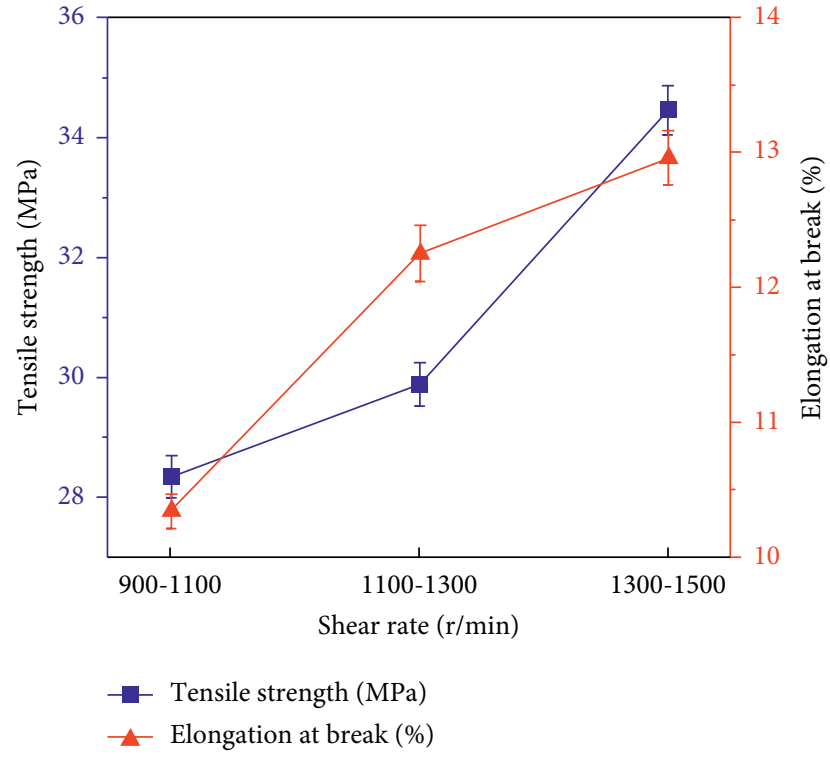

(a)

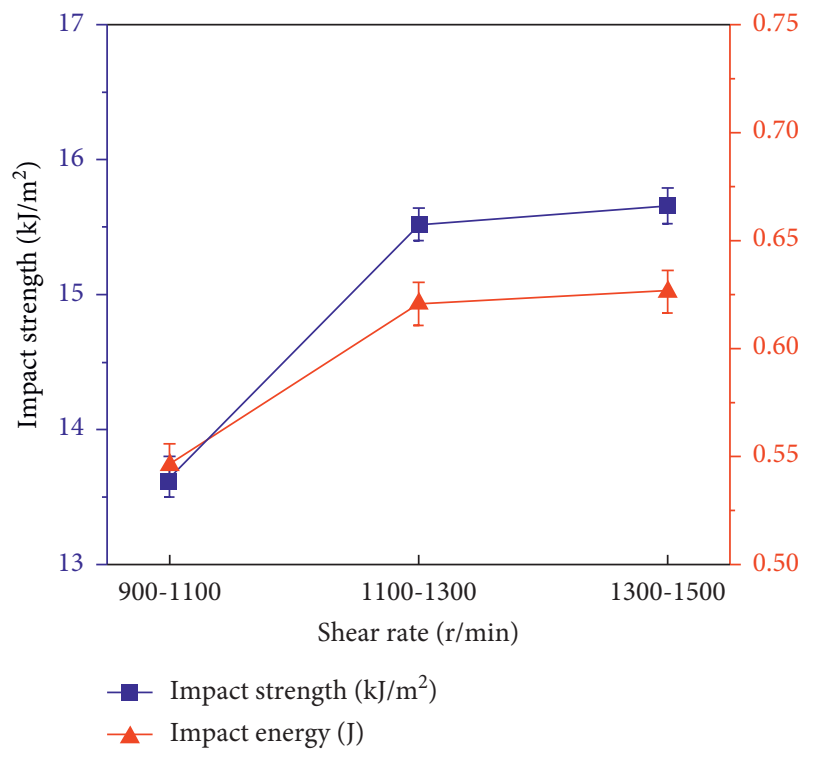

(c)

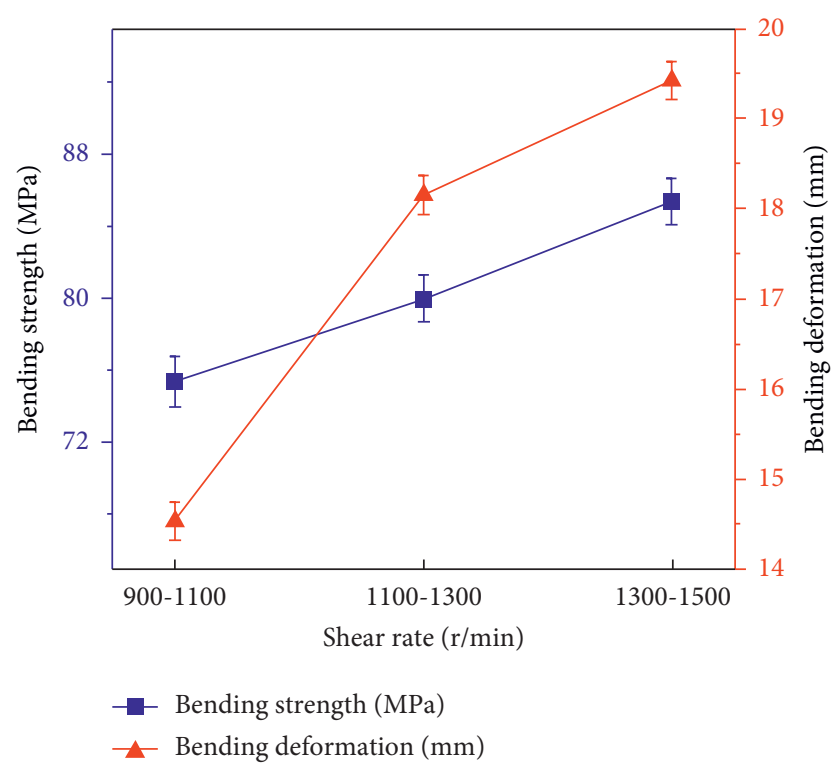

(b)

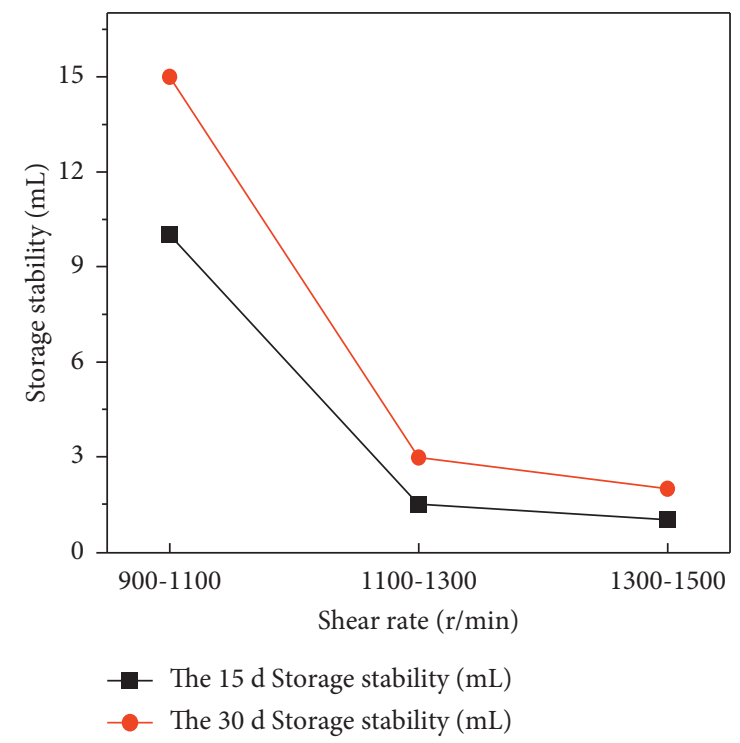

(d)

FIgURE 4: Effect of shear rate on properties of emulsifier A emulsifying E-51 epoxy resin: (a) Tensile properties; (b) bending properties; (c) impact properties; (d) stability.

effect of emulsifier content on the properties of waterborne epoxy resin was determined. The test results are shown in Figures 6 and 7.

Figure 6 shows that, with the increase of emulsifier A content, the tensile properties, bending properties, and impact properties of waterborne epoxy resins generally increase first and then decrease, and the stability of emulsion gradually improves. When the content of emulsifier $\mathrm{A}$ is increased to $18 \%$, the elongation at break of the cured waterborne epoxy resin reaches the maximum value of $12.96 \%$. Meanwhile, the deformation ability and impact resistance of waterborne epoxy resin reach the maximum, changing from brittle fracture to nonfracture at $180^{\circ}$ bending. The bending strength, bending deformation, and impact strength are $85.37 \mathrm{MPa}, 19.42 \mathrm{~mm}$, and $15.66 \mathrm{~kJ} / \mathrm{m}^{2}$, respectively. It shows improved deformation ability and impact resistance. It is suggested that the content of emulsifier A is $18 \%$. The analysis shows that on the one hand, with the increase of emulsifier content, the emulsifying effect of epoxy resin gradually increases, the particle size of emulsion gradually decreases, and the properties of waterborne epoxy resin gradually improve. However, the excess emulsifier causes the performance of the epoxy resin to decrease. On the other hand, the emulsifier can toughen the waterborne epoxy resin to a certain extent. With the increase of emulsifier content, its deformation ability and impact resistance increase, but its tensile strength decreases gradually. 


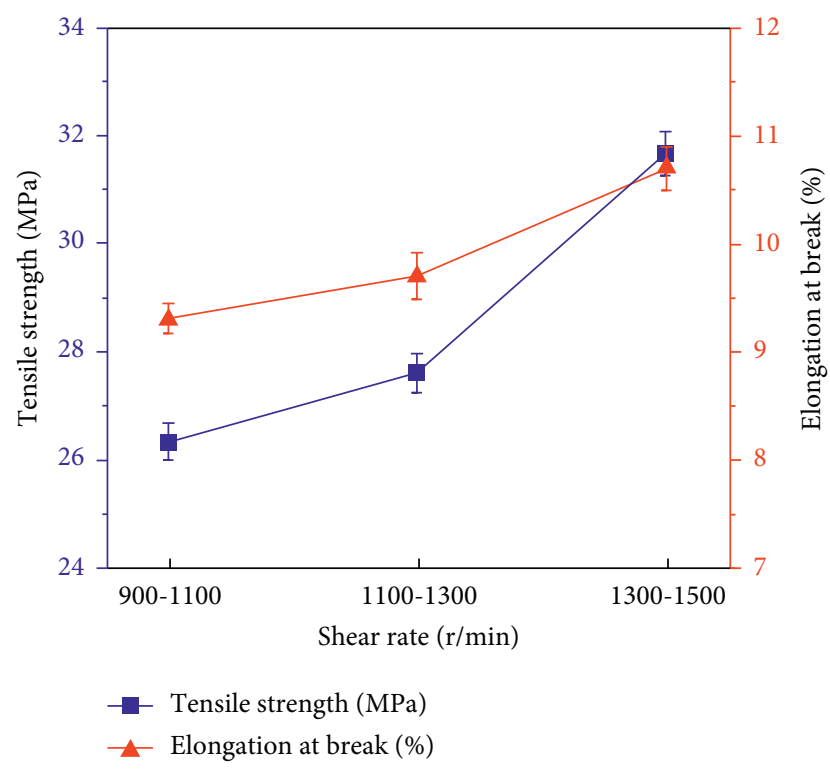

(a)

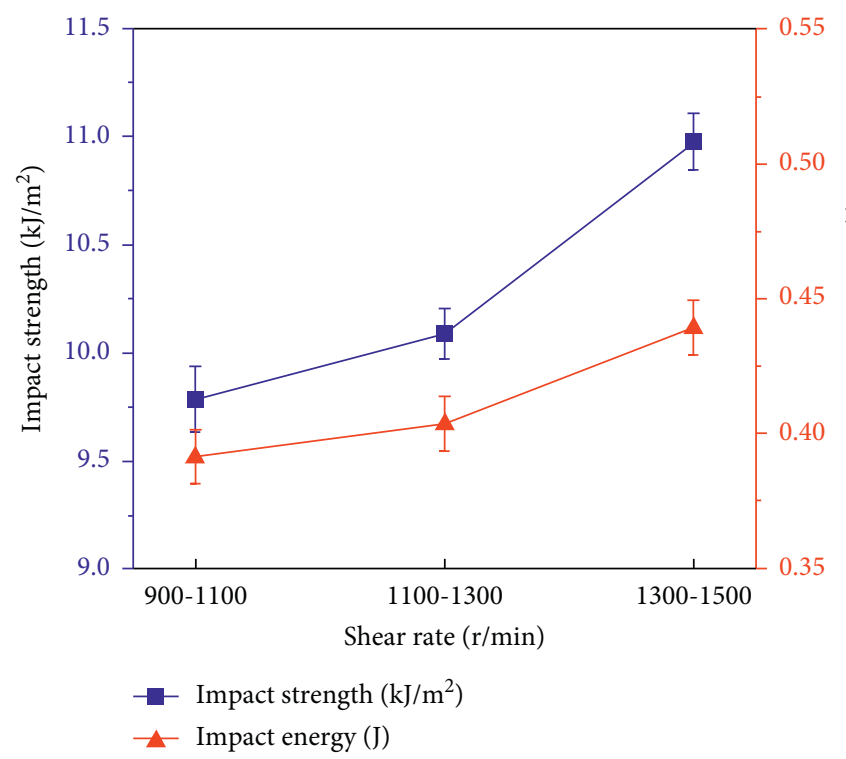

(c)

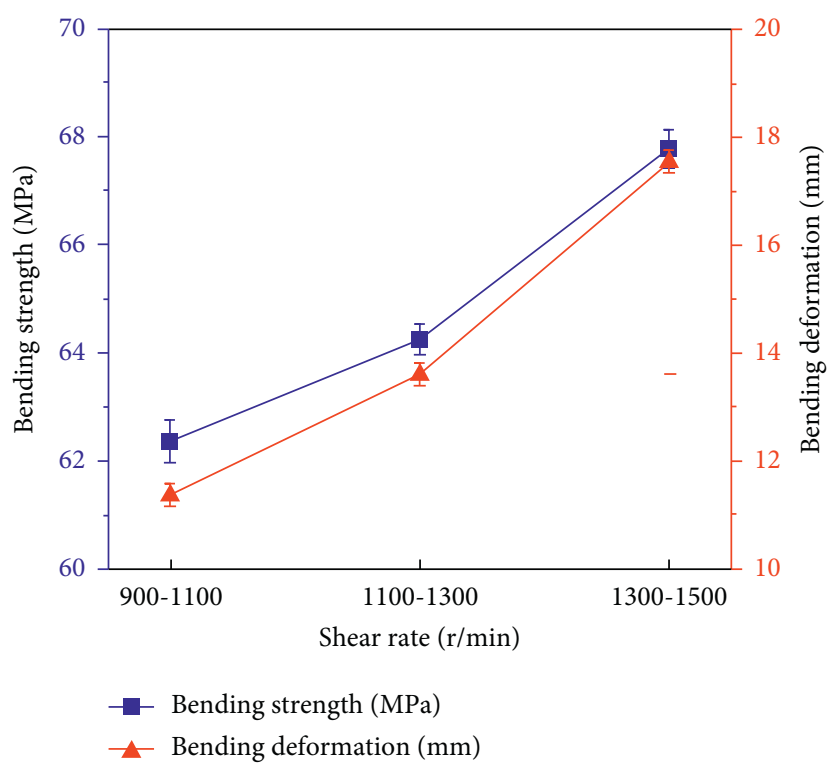

(b)

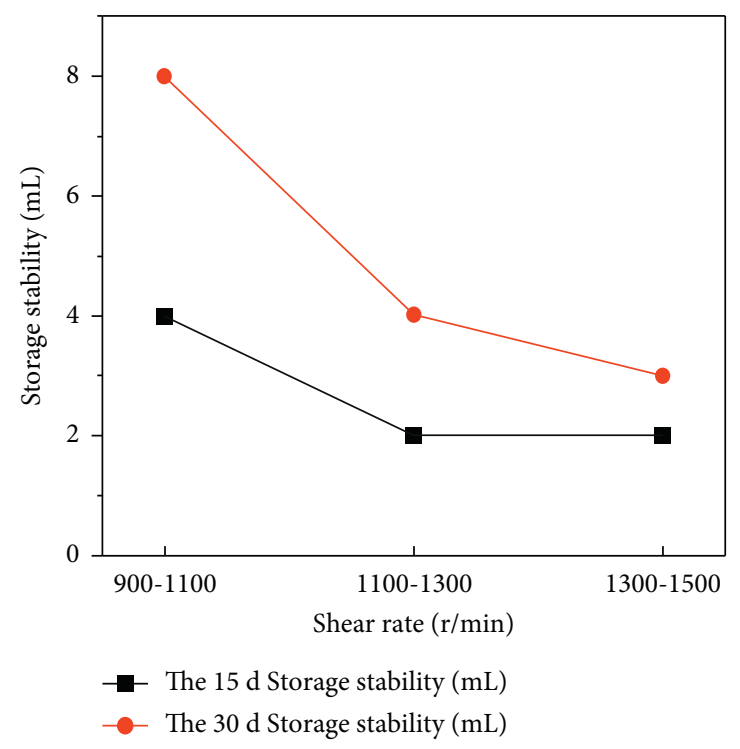

(d)

Figure 5: Effect of shear rate on properties of emulsifier B emulsifying E-51 epoxy resin: (a) Tensile properties; (b) bending properties; (c) impact properties; (d) stability.

It can be seen from Figures 6 and 7 that the properties of waterborne epoxy resin prepared with emulsifier B are similar to those prepared with emulsifier $\mathrm{A}$. When the content of emulsifier B is increased to $16 \%$, the elongation at break of the cured waterborne epoxy resin reaches the maximum value of $12.11 \%$. Meanwhile, the deformation ability and impact resistance of waterborne epoxy resin reach the best, changing from brittle fracture to non-fracture at $180^{\circ}$ bending. The bending strength, bending deformation, and impact strength are $76.87 \mathrm{MPa}, 17.79 \mathrm{~mm}$, and $15.44 \mathrm{~kJ} / \mathrm{m}^{2}$, respectively. It is suggested that the content of emulsifier B is $16 \%$. Compared with the waterborne epoxy resin prepared by using emulsifier $\mathrm{B}$, the waterborne epoxy resin prepared by emulsifier $\mathrm{A}$ has better mechanical strength and deformation ability.

3.3. Bonding Properties of Waterborne Epoxy Resin. The pullout strength of waterborne epoxy resin prepared by emulsifier A or emulsifier B at different temperatures was tested to evaluate its bonding performance. The test results are shown in Figure 8.

It can be seen from Figure 8 that with the increase of test temperature, the bonding performance of waterborne epoxy resin shows a gradually decreasing trend. When the test temperature increases from $-10^{\circ} \mathrm{C}$ to $25^{\circ} \mathrm{C}$ and from 


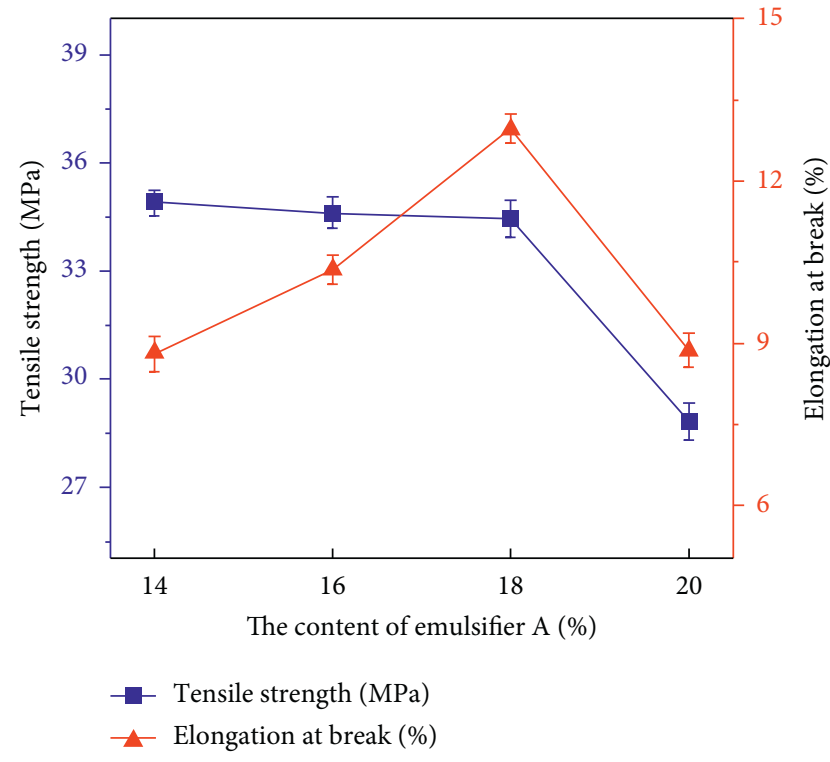

(a)

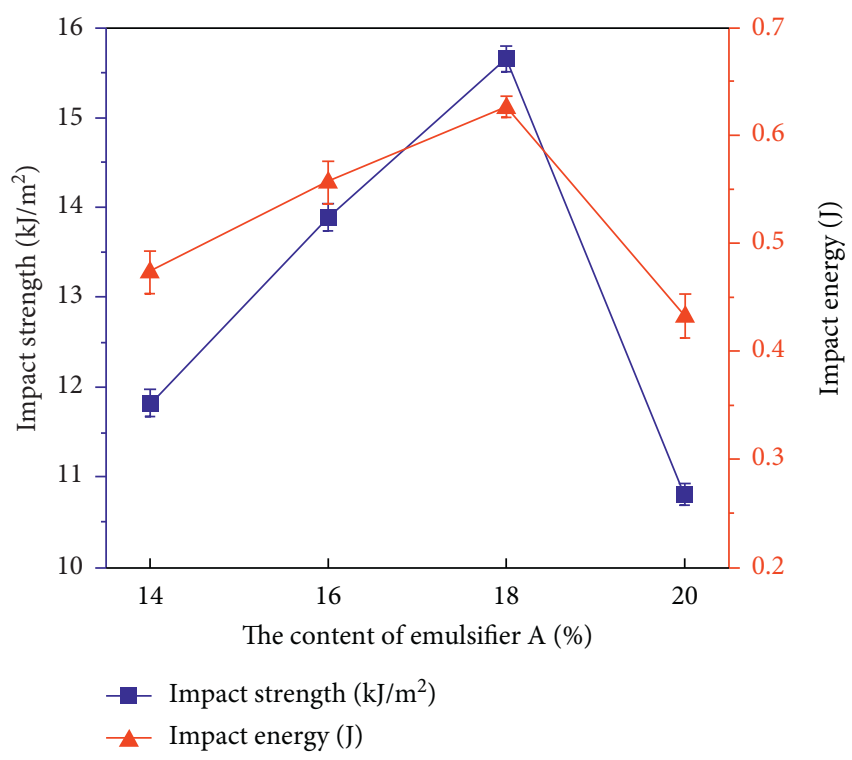

(c)

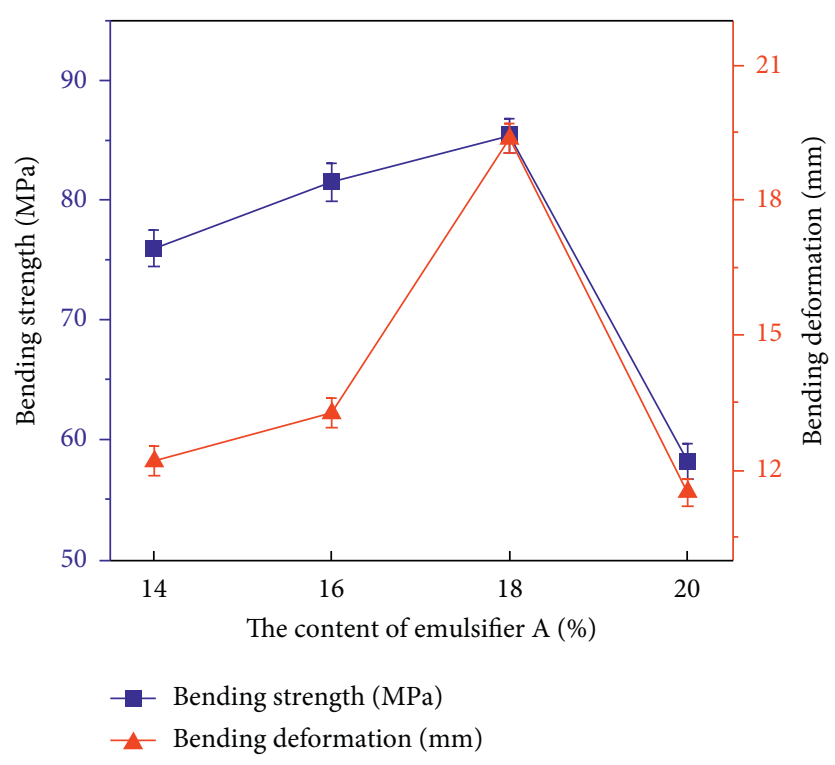

(b)

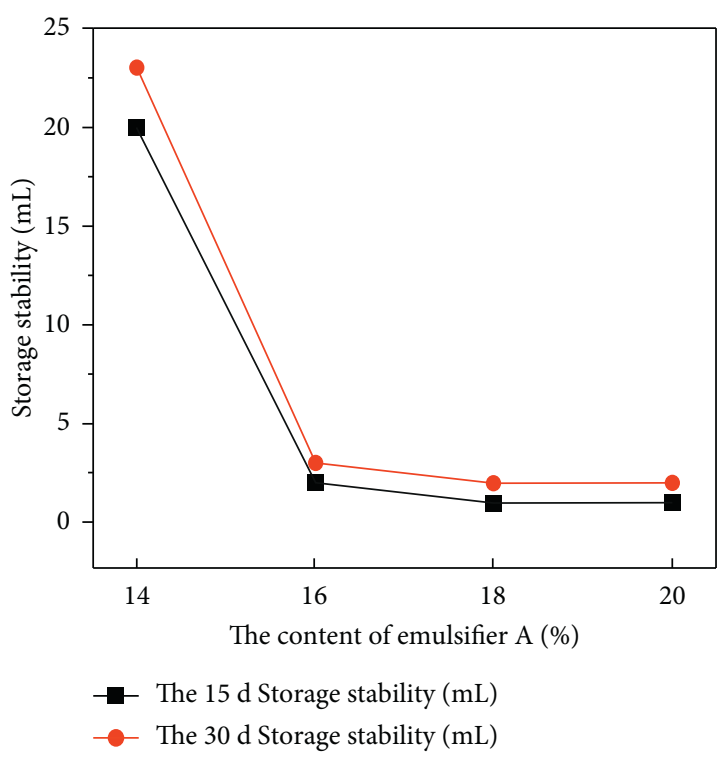

(d)

Figure 6: Effect of emulsifier A content on properties of E-51 waterborne epoxy resin: (a) Tensile properties; (b) bending properties; (c) impact properties; (d) stability.

$25^{\circ} \mathrm{C}$ to $40^{\circ} \mathrm{C}$, the pull-out strength of waterborne epoxy resin decreases slightly by about $0.1 \mathrm{MPa}$ and $0.2 \mathrm{MPa}$, respectively. The $40^{\circ} \mathrm{C}$ pull-out strength of waterborne epoxy resin prepared by these two emulsifiers are 2.02 $\mathrm{MPa}$ and 1.95 $\mathrm{MPa}$, respectively, which still showed good bonding performance. At different test temperatures, the pull-out strength of waterborne epoxy resin prepared by emulsifier A was slightly higher than that prepared by emulsifier B, showing better bonding performance.
3.4. Comprehensive Evaluation on Properties of Waterborne Epoxy Resin. To comprehensively evaluate the properties of waterborne epoxy resin prepared by using the phase inversion method, a multi-index grey target decision model was introduced. At the same time, its properties were compared with those of waterborne epoxy resin prepared by using the curing agent emulsification method. According to the multi-index grey target decision model in reference [25], the sample matrix as shown in Table 2 is constructed, and each evaluation index is a benefit index. 


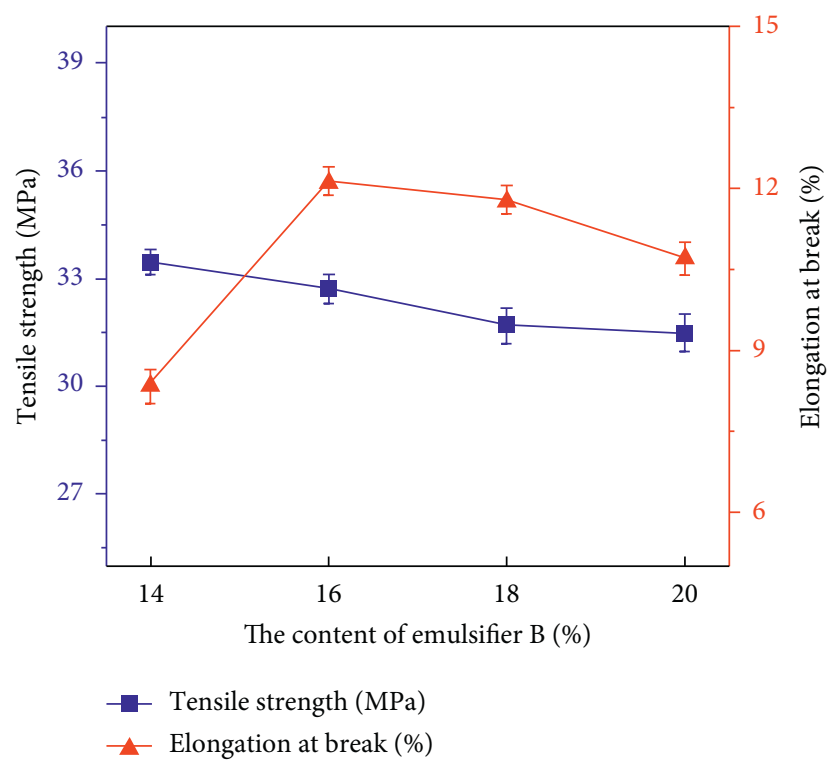

(a)

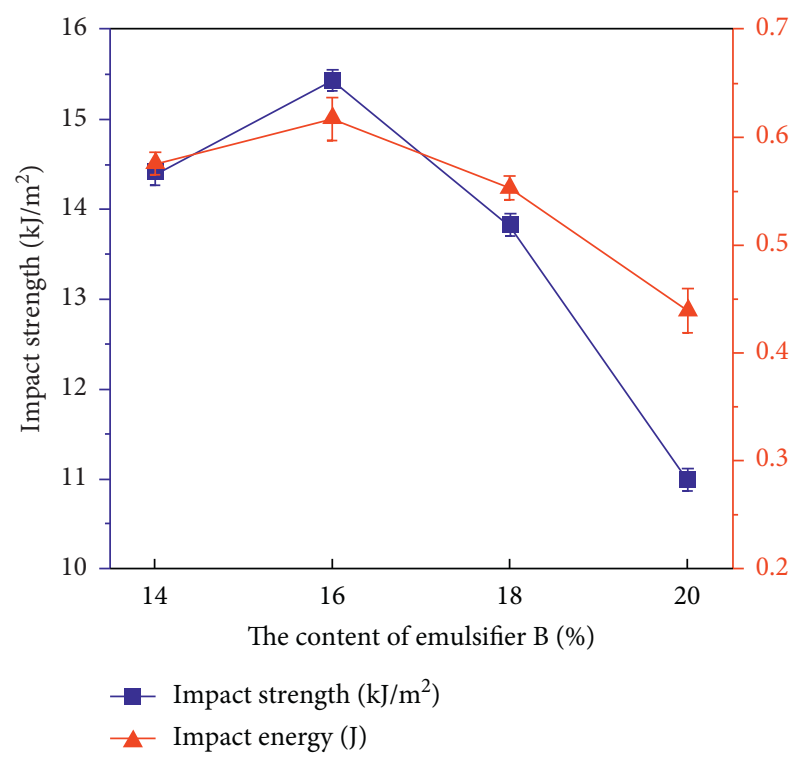

(c)

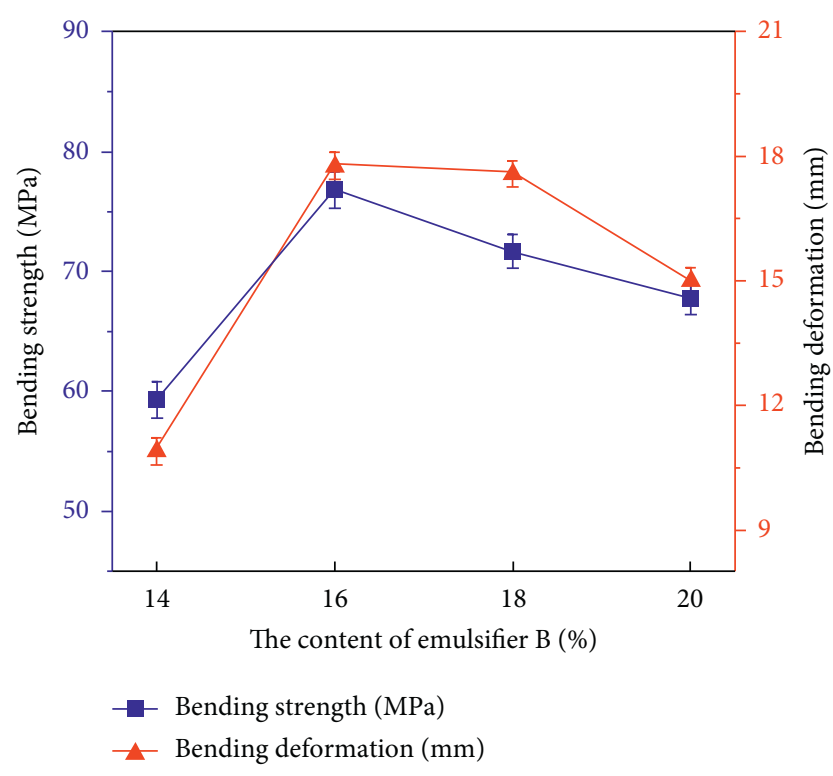

(b)

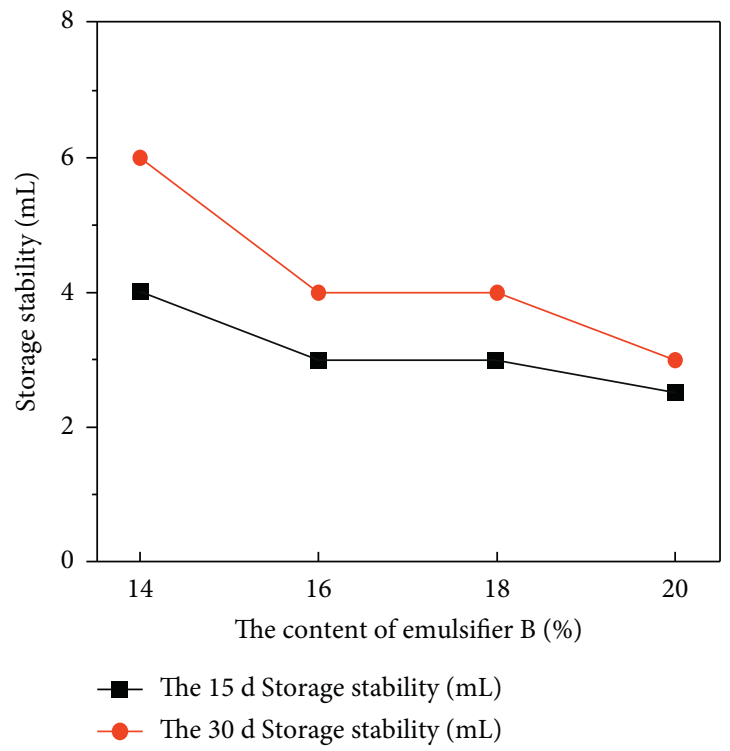

(d)

Figure 7: Effect of emulsifier B content on properties of E-51 waterborne epoxy resin: (a) Tensile properties; (b) bending properties; (c) impact properties; (d) stability.

According to the calculation steps in reference [25], the sample matrix (Table 2) is standardized, and the off-target of the grey target decision model is calculated. With the target of minimizing the off-target distance, the optimal weight vector of each index is calculated, and the comprehensive off-target distance of each scheme is finally determined. The results are shown in Table 3.

It can be seen from Tables 2 and 3 that the comprehensive off-target distance of scheme 1 is the smallest, which is 0.01087 . It indicates that the waterborne epoxy resin prepared with emulsifier $A$ has the best comprehensive properties, such as better mechanical strength, deformation ability, and bonding performance. This result is consistent with the preliminary conclusion obtained in the test process. It indicates that the multiindex grey target decision model is suitable for the evaluation of the comprehensive properties of waterborne epoxy resin. In addition, the waterborne epoxy resin prepared by using the phase inversion method has better construction advantages. Therefore, it is suggested to use the phase inversion method to prepare waterborne epoxy resin. 


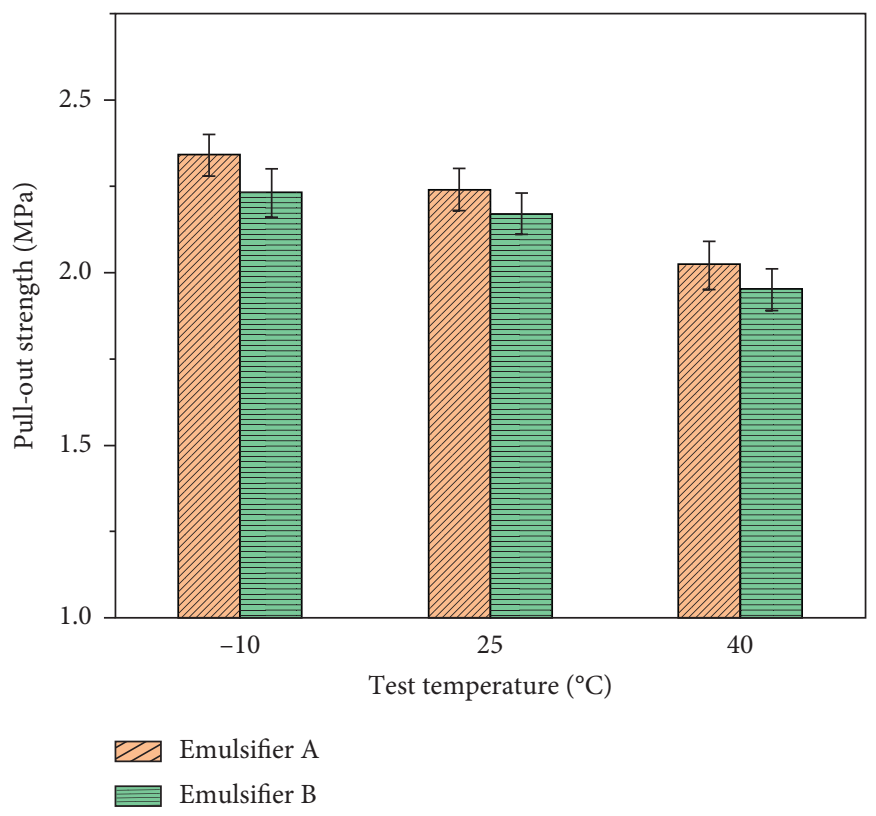

FIGURE 8: The bonding performance of waterborne epoxy resin.

TABLE 2: The performance test results of waterborne epoxy resin.

\begin{tabular}{|c|c|c|c|c|c|c|c|}
\hline Scheme & Emulsifier type & $\begin{array}{c}\text { Tensile } \\
\text { strength }(\mathrm{MPa})\end{array}$ & $\begin{array}{c}\text { Elongation at } \\
\text { break (\%) }\end{array}$ & $\begin{array}{c}\text { Bending } \\
\text { strength (MPa) }\end{array}$ & $\begin{array}{c}\text { Bending } \\
\text { deformation } \\
(\mathrm{mm})\end{array}$ & $\begin{array}{c}\text { Impact strength } \\
\left(\mathrm{kJ} / \mathrm{m}^{2}\right)\end{array}$ & $\begin{array}{l}\text { The } 25^{\circ} \mathrm{C} \text { bonding } \\
\text { strength }(\mathrm{MPa})\end{array}$ \\
\hline 1 & A & $34.46 \pm 0.36$ & $12.96 \pm 0.15$ & $85.37 \pm 0.45$ & $19.42 \pm 0.18$ & $15.66 \pm 0.21$ & $2.24 \pm 0.11$ \\
\hline 2 & B & $32.72 \pm 0.32$ & $12.11 \pm 0.14$ & $76.87 \pm 0.42$ & $17.79 \pm 0.18$ & $15.44 \pm 0.22$ & $2.17 \pm 0.09$ \\
\hline 3 & $\begin{array}{l}\text { Curing agent } \\
\text { emulsification }\end{array}$ & $27.84 \pm 0.29$ & $12.76 \pm 0.14$ & $82.50 \pm 0.46$ & $22.99 \pm 0.21$ & $14.63 \pm 0.19$ & $2.15 \pm 0.10$ \\
\hline
\end{tabular}

TABLE 3: The comprehensive off-target distance of different waterborne epoxy resin preparation schemes.

\begin{tabular}{lcc}
\hline Scheme & Emulsifier type & The off-target distance \\
\hline 1 & $\mathrm{~A}$ & 0.01087 \\
2 & $\mathrm{~B}$ & 0.03333 \\
3 & Curing agent emulsification & 0.03139 \\
\hline
\end{tabular}

\section{Conclusion}

(1) The optimum preparation parameters for the preparation of waterborne epoxy resin by using the phase inversion method were shear time $1.5 \mathrm{~h}$, shear temperature $60^{\circ} \mathrm{C}$, and shear rate $1300-1500 \mathrm{r} / \mathrm{min}$. The suitable contents of emulsifier A and B are 18\% and $16 \%$, respectively.

(2) The tensile strength, elongation at break, bending strength, bending deformation, and impact strength of waterborne epoxy resin prepared by emulsifier A can reach $34.46 \mathrm{MPa}, 12.96 \%, 85.37 \mathrm{MPa}, 19.42 \mathrm{~mm}$, and $15.66 \mathrm{~kJ} / \mathrm{m}^{2}$, respectively. It shows improved mechanical strength, deformation ability, and impact resistance.

(3) With the increase of test temperature, the interlaminar bonding properties of waterborne epoxy resin decreased gradually, but its $40^{\circ} \mathrm{C}$ bonding strength was still about $2.0 \mathrm{MPa}$. The waterborne epoxy resin prepared by emulsifier A showed better bonding performance.

(4) The waterborne epoxy resin prepared by emulsifier A has the best comprehensive properties. This result is consistent with the preliminary conclusion obtained in the test process. It indicates that the multi-index grey target decision model is suitable for the evaluation of the comprehensive properties of waterborne epoxy resin.

(5) The preparation process parameters of waterborne epoxy resin were optimized. The mechanical properties, stability, and bonding properties of waterborne epoxy resin were comprehensively evaluated. It is necessary to further study the performance and application of waterborne epoxy resin modified emulsified asphalt.

\section{Data Availability}

Some or all data, models, or code generated or used during the study are available from the corresponding author upon request. 


\section{Conflicts of Interest}

The authors declare that they have no conflicts of interest regarding the publication of this paper.

\section{Acknowledgments}

This research was sponsored by the Shandong Hi-Speed Group Co., Ltd. Maintenance Technology Project (QLTD2019-A-FW-0059), Key Research and Development Project in Shaanxi Province (2021GY-206), and the Fundamental Research Funds for the Central Universities (300102219314).

\section{References}

[1] Z. D. Wang, G. D. Meng, L. L. Wang et al., "Simultaneously enhanced dielectric properties and through-plane thermal conductivity of epoxy composites with alumina and boron nitride nanosheets," Scientific Reports, vol. 11, no. 1, pp. 1-11, 2021.

[2] Z. Wang, X. Wang, S. Wang et al., "Simultaneously enhanced thermal conductivity and dielectric breakdown strength in sandwich AlN/epoxy composites," Nanomaterials, vol. 11, no. 8, p. 1898, 2021.

[3] X. Yang, X. Zhong, J. Zhang, and J. Gu, "Intrinsic high thermal conductive liquid crystal epoxy film simultaneously combining with excellent intrinsic self-healing performance," Journal of Materials Science \& Technology, vol. 68, pp. 209-215, 2021.

[4] K. Ruan, X. Zhong, X. Shi, J. Dang, and J. Gu, "Liquid crystal epoxy resins with high intrinsic thermal conductivities and their composites: a mini-review," Materials Today Physics, vol. 20, Article ID 100456, 2021.

[5] Q. Xiang and F. Xiao, "Applications of epoxy materials in pavement engineering," Construction and Building Materials, vol. 235, Article ID 117529, 2020.

[6] Editorial Department of China Journal of Highway and Transport, "Review on China's pavement engineering Research.2020," China Journal of Highway and Transport, vol. 33, no. 10, pp. 1-66, 2020.

[7] Q. Chen, S. Wang, C. Wang, F. Wang, H. Fu, and X. Yang, "Modified waterborne epoxy as a cold pavement binder: preparation and long-term working properties," Journal of Materials in Civil Engineering, vol. 33, no. 5, Article ID 04021079, 2021.

[8] Q. Chen, Y. Lu, C. Wang, B. Han, and H. Fu, "Effect of raw material composition on the working performance of waterborne epoxy resin for road," International Journal of Pavement Engineering, pp. 1-12, 2020.

[9] H. Fu, C. Wang, G. Yu, Q. Chen, and L. Liu, "Design optimization and performance evaluation of the open graded friction course with small particle size aggregate," Advances in Civil Engineering, vol. 2021, Article ID 6668378, 2021.

[10] C. Wang, S. Wang, Z. Gao, and Z. Song, "Effect evaluation of road piezoelectric micro-energy collection-storage system based on laboratory and on-site tests," Applied Energy, vol. 287, Article ID 116581, 2021.

[11] H. Fu, C. Wang, L. Niu, G. Yang, and L. Liu, "Composition optimisation and performance evaluation of waterborne epoxy resin emulsified asphalt tack coat binder for pavement," International Journal of Pavement Engineering, pp. 1-15, 2021.

[12] G. Yang, C. Wang, H. Fu, Z. Yan, and W. Yin, "Waterborne epoxy resin-polyurethane-emulsified asphalt: preparation and properties," Journal of Materials in Civil Engineering, vol. 31, no. 11, Article ID 04019265, 2019.

[13] G. Yang, C. Wang, P. Wen, and W. Yin, "Performance characteristics of cold-mixed porous friction course with composite-modified emulsified asphalt," Journal of Materials in Civil Engineering, vol. 32, no. 3, Article ID 04019372, 2020.

[14] J. Ji, Y. Hui, W. Zheng, X. Ying, S. Han, and X. Shifa, "Preparation and properties of waterborne epoxy-modified emulsified asphalt binder (WEMEAB)," Journal of Testing and Evaluation, vol. 48, no. 4, pp. 3172-3187, 2018.

[15] J. Ji, L. H. Liu, Z. Suo, X. U. Ying, S Yang, and S. F. Xu, "Performances of micro-surfacing with waterborne epoxy resin modified emulsified asphalt," Journal of Chang'an University (Natural Science Edition), vol. 37, no. 5, pp. 23-30, 2017, In Chinese.

[16] C. Wang, Q. Chen, T. Guo, and Q. Li, "Environmental effects and enhancement mechanism of graphene/tourmaline composites," Journal of Cleaner Production, vol. 262, Article ID 121313, 2020

[17] X. J. Li, S. Z. Gao, L. H. Zhao et al., "Evaluation on performances of cold recycling mixture with foamed bitumen with waterborne epoxy resin," Journal of Building Materials, pp. 1-14, 2021, In Chinese.

[18] M. Liu, S. Han, J. Pan, and W. Ren, "Study on cohesion performance of waterborne epoxy resin emulsified asphalt as interlayer materials," Construction and Building Materials, vol. 177, pp. 72-82, 2018.

[19] S. Han, T. Yao, X. Han, Z. Hongwei, and X. Yang, "Performance evaluation of waterborne epoxy resin modified hydrophobic emulsified asphalt micro-surfacing mixture," Construction and Building Materials, vol. 249, Article ID 118835, 2020.

[20] R. Li, Z. Leng, Y. Zhang, and X. Ma, "Preparation and characterization of waterborne epoxy modified bitumen emulsion as a potential high-performance cold binder," Journal of Cleaner Production, vol. 235, pp. 1265-1275, 2019.

[21] R. Li, Z. Leng, M. N. Partl, and C. Raab, "Characterization and modelling of creep and recovery behaviour of waterborne epoxy resin modified bitumen emulsion," Materials and Structures, vol. 54, no. 1, p. 8, 2021.

[22] C. H. Nie, J. H. Chen, and J. Q. Hu, "Research progress of waterborne epoxy resin," Fine Chemicals, vol. 36, no. 7, pp. 1279-1285+1293, 2019, In Chinese.

[23] Y.X. Jin and H. L. Lian, "Research progress in phase inversion emulsification technique of epoxy resin," Paint \& Coatings Industry, vol. 48, no. 9, pp. 70-76, 2018, In Chinese.

[24] K. Chen, J. Q. Ma, and Z. Y. Yin, "Synthesis and application of bifunctional epoxy emulsifier," Fine Chemicals, vol. 33, no. 05, pp. 524-529, 2016, In Chinese.

[25] Q. Chen, C. Wang, P. Wen, X. Sun, and T. Guo, "Performance evaluation of tourmaline modified asphalt mixture based on grey target decision method," Construction and Building Materials, vol. 205, pp. 137-147, 2019. 